\title{
Nurses' Knowledge and Practices in Cases of Acute and Chronic Confusion: A Questionnaire Survey
}

\author{
Francisco M. C. Sampaio, RN, MSc, PhD Candidate, and Carlos Sequeira, RMHN, MSc, PhD \\ Francisco M. C. Sampaio, MSc, PhD candidate, is a Registered Nurse at Psychiatry Department, Hospital de Braga, Braga, Portugal, Editorial Board \\ Coordinator of Portuguese Journal of Mental Health Nursing, and Member of The Portuguese Society of Mental Health Nursing Management Board; \\ and Carlos Sequeira, RMHN, MSc, PhD, is a Full Professor at Scientific Pedagogical Unit "Nursing: Discipline \& Profession," Porto Nursing School, \\ Porto, Portugal, Coordinator of the Research Group "NurID: Innovation \& Development in Nursing" —CINTESIS-FMUP, Director of Portuguese Journal \\ of Mental Health Nursing, and President of The Portuguese Society of Mental Health Nursing.
}

\section{Search terms: \\ Confusion, delirium, dementia, knowledge, nurse}

\section{Author contact: \\ Francisco.Sampaio@hospitaldebraga.pt, with a copy to the Editor: gpearson@uchc.edu}

\section{Conflict of Interest Statement}

The authors report no actual or potential conflicts of interest. No external or intramural funding was received.

First Received November 11, 2013; Final Revision received February 10, 2014; Accepted for publication February 20, 2014
PURPOSE: This study aimed to describe nurses' knowledge and practices toward patients with acute or chronic confusion.

DESIGN AND METHODS: A cross-sectional design was used, and 249 nurses engaged in clinical practice fulfilled an online self-report questionnaire.

FINDINGS: Tools for diagnosing acute confusion/delirium are never used by $57.80 \%$ of the nurses. Between $80 \%$ and $81 \%$ of nursing interventions involve managing patients' physical environment and between $62 \%$ and $71 \%$ deal with managing communication. Theoretical training in the use of tools for assessing and intervening in cases of confusion was significantly associated with nurses' knowledge and practices.

PRACTICE IMPLICATIONS: These results suggest the need for increased investment in nurses' training.

doi: 10.1111/ppc.12069

Acute confusion (AC) and chronic confusion (CC) are frequently associated, respectively, with delirium and dementia and are frequently diagnosed by nurses when dealing with the elderly. A study by Passos, Sequeira, and Fernandes (2012) identified confusion (specifically CC) in $43.7 \%$ of patients in a psychiatry ward in people 65 years or older. On the other hand, Neves (2008) found that $20.5 \%$ of elderly patients hospitalized in general manifested the nursing diagnosis "Acute Confusion."

Several studies have pointed out insufficiencies in the assessment, diagnosis, and intervention with elderly patients with AC. For example, Scott, McIlveney, and Mallice (2013) found that only $5.6 \%$ of nurses evaluated intensive care patients' levels of delirium while Forsgren and Eriksson (2010) observed that, in $44 \%$ of cases, no formal tool was used to diagnose AC. Moreover, in a sample of 601 intensive care nurses, Devlin et al. (2008) discovered that only 3\% of nurses found it important to assess delirium. The nurses in question cited difficulties in assessing delirium in intubated patients as well as the complexity of available instruments. Research to data appears to support the underdiagnosis of $\mathrm{AC} /$ delirium in
Portugal. Silva, Silva, and Marques (2011) observed that although only $12.6 \%$ of nurses identified AC/delirium in the nursing records, $30.6 \%$ of them had cited a perception of $\mathrm{AC} /$ delirium, while only $4.5 \%$ of patients' charts contained information regarding the diagnosis.

Marques (2012) found that nurses' AC intervention focused on the management of physical environment, vigilance, and the restriction of patients, despite the importance in the literature of other forms of intervention such as orientation (Sendelbach, Guthrie, \& Schoenfelder, 2009) and discharge planning (Cole, Williams, \& Williams, 2006). These lacunas are not surprising when the lack of knowledge about approaches to dealing with $\mathrm{AC} /$ delirium is taken into consideration. In Belgium, for example, a study of acute geriatric wards found that only $26.2 \%$ had written policies for managing delirium while, hospital-wide, only $15.4 \%$ wards had such explicit guidelines (Steen et al., 2013). Although most of these geriatric wards had either written or verbal guidelines for preventing delirium, few had written protocols for identifying the causes $(15.4 \%)$ or managing delirium (13.8\%). 
The results mentioned relate specifically to cases of AC. However, in cases of CC, the situation does not appear to differ greatly. Following a study of the Nursing Minimum Data Set of a hospital in the United States, Park, Delaney, Maas, and Reed (2004) observed that out of 502 cases of elderly patients with dementia only $13.1 \%$ had the intervention "confusion management" drawn up and carried out.

The situation above prompted the current investigation that was designed to elucidate the nursing context regarding the knowledge and practices related to the diagnosis of $\mathrm{AC} /$ delirium and its interventions and to the intervention in cases of patients with CC. This study focused on nurse care in the phases of assessment, diagnosis, intervention, as well as their outcomes. It was designed with two main goals. Firstly, it sought to describe the knowledge and the implementation of diagnosis in cases of patients with $\mathrm{AC} /$ delirium, and of intervention in cases of patients with $\mathrm{AC} /$ delirium and CC. Secondly, it looked for any relationships between the demographic profile of nurses and their knowledge and practices in evaluating and intervening in cases of patients with confusion. The following research questions guided the study: (a) What diagnostic knowledge do nurses have and how do they put it into practice when diagnosing AC/delirium? (b) What knowledge do nurses have and how do they put it into practice in AC/delirium and CC interventions? (c) What is the relationship between the demographic profile of the nurses and their knowledge and practice of $\mathrm{AC} /$ delirium diagnoses? (d) What relationship exists between the demographic profile of the nurses and the nursing interventions provided in $\mathrm{AC} /$ delirium and CC cases?

\section{Method}

\section{Study Design and Ethics}

This is a descriptive, cross-sectional, quantitative research project carried out using a self-report questionnaire. This method was judged to be the quickest and least expensive approach to gathering information from a wide range of people. It also offered a high degree of impersonality, uniform instructions (ensuring consistency between questionnaires), and thus guaranteed anonymity of the answers, which put respondents at ease and encouraged them to freely offer their opinions (Fortin, Côté, \& Filion, 2009).

The study was authorized by the Ethics Committee of The Portuguese Society of Mental Health Nursing. The participants were informed about the study design by information at the top of the questionnaire, as well as about the objectives of the investigation. Participants were also promised confidentiality and that their data would remain anonymous. The survey met the guidelines set out in the Helsinki Declaration.

\section{Sampling}

The target population is made up of nurses working in clinical contexts, actively involved in caregiving. Given the impossibility of gaining access to the entire population, the following sample was chosen using two selection criteria: (a) participants had to be Portuguese nurses, working in Portugal; (b) they had to be actively engaged in nursing care. Considering that the sample has its origin in Portugal, and that Portugal has some particularities regarding the nursing profession, it is important to present some of those singularities. Thus, the nursing course is a degree course of 4 years duration that leads to the title of registered nurse. Registered nurses can take up a specialization in one of the following areas: medical-surgical, psychiatric and mental health, child health and pediatrics, maternal health and obstetrics, public health, or rehabilitation. Beyond the specialization, nurses also have the possibility of taking up a master's degree in the specialization area (or in other areas), as well as a PhD in Nursing.

A non-probabilistic sample was selected by snowball. Despite the limitations associated with this sampling strategy, this option was taken in order to reach participants from different geographical locations and wards, and with different training pathways who, otherwise, could not be included in the data collection. Although there is no major difference in regulations, practice, and funding of Portuguese nurses in different locations and wards, the aim of the sampling strategy was to collect data from nurses who work in public and private healthcare institutions of the whole country, and in wards with different practice "complexity" levels. The questionnaire was sent by e-mail to nurses (on the list of contacts of the investigators and on the distribution lists of national nursing journals). At a later moment, we sought to disseminate the questionnaire to other nurses meeting the criteria using other means, including social networks.

\section{Self-Report Questionnaire}

In order to understand the knowledge and practices of Portuguese nurses regarding the assessment of $\mathrm{AC} /$ delirium patients as well as their efforts to care for patients with acute and CC, we specially designed our own self-report questionnaire, since none was found during the literature review.

The first draft included 20 questions intended to gather both qualitative and quantitative data. A brief explanation of the objectives of the research was also included as well as the selection criteria for participation and a request to forward the questionnaire to other qualifying nurses. Respondents also received the e-mail of the principal investigator in case of questions. Five $\mathrm{AC}$ and $\mathrm{CC}$ experts reviewed the questionnaire, two of whom with PhDs in Nursing Sciences, a psychia- 
trist, and two nurses specialized in Psychiatric and Mental Health Nursing. The experts' final consensus was a version with a total of 24 questions (the last two of which were divided into two parts).

The first eight questions gathered demographic data (age, gender, length of professional experience, academic degree, professional title, including nursing specialization, number of postgraduate nursing training courses, theoretical training in the use of assessment instruments, and theoretical training in the assessment and intervention for confusion). Further questions sought to know the nurses' level of literacy regarding psychometric evaluation tools (Adamis, Sharma, Whelan, \& Macdonald, 2010; Rapp et al., 2000; Wong, Holroyd-Ledue, Simel, \& Straus, 2010) potentially useful for measuring $\mathrm{AC} /$ delirium, as well as the principal approaches for caring for $\mathrm{AC}$ and/or CC used by nurses in health organizations. Participants were also asked about their opinions regarding the quality and regularity of nursing practices in this area.

Following the design of the questionnaire written in accordance with the literature review undertaken and intended to gather information about the topic of study, the instrument was subject to a pretest by five nurses (precluded from participating in the final survey) in order to judge the operationalization of the instrument. No alterations were suggested and the survey was therefore maintained according to its original format. The questionnaire took approximately 10 min to complete. It was drawn up using Google Drive ${ }^{\circledR}$ and was completed online with all the answers automatically extracted and transferred to an Excel database.

\section{Data Analysis}

The completed questionnaires were immediately coded in order to guarantee the anonymity of the participants and the confidentiality of the data. Quantitative data were entered into IBM SPSS Statistics 21.0 for Macintosh. The qualitative data were subjected to a latu sensu content analysis, which, in turn, led to the identification of categories that were included in the SPSS data for analysis.

At an initial stage, descriptive statistics were used to characterize the sample and to describe the phenomenon under study. Inferential statistics were later applied to identify any potential relationships between the demographic profiles of the nurses and their knowledge and practices regarding the assessment and intervention in patients suffering from confusion.

Parametric tests such as the Student's $t$-test, the one-way analysis of variance, and the Pearson's correlation coefficient were utilized. Every time a dependent variable with interval data (or any other condition such as the presence of similarities between the variables in different groups) was not met, a nonparametric test was used instead (such as the MannWhitney, Kruskal-Wallis, Spearman's correlation coefficient, or the chi-square-with the subsequent application of a Cramér's V association test). The level of significance was set at $p<.05$.

\section{Results}

Two hundred and forty-nine questionnaires were fully completed. Table 1 illustrates the respondents, $68.7 \%$ of which were women, with a mean age of 33.8 (SD: 8.08) and a mean length of professional experience of 11 years (SD: 7.91). Mostly $71.90 \%$ had just a university nursing degree and less than one postgraduate nursing degree. Most participants lacked any specialist nursing title (58.60\%). Furthermore, most participants $(68.10 \%)$ worked in hospital wards, particularly in the medical-surgical (45.20\%) and mental health $(23.40 \%)$ areas. A large majority had received theoretical training in evaluation tools $(79.50 \%)$, yet $47.80 \%$ lacked any training in evaluating and caring for confusion.

A significant number of respondents $(78.30 \%)$ indicated that no systematized evaluation of AC was normally

Table 1. Sample Characteristics

\begin{tabular}{lrrl}
\hline Demographics & $\boldsymbol{n}$ & $\%$ & $\boldsymbol{M}$ \\
\hline Gender & 171 & 68.70 & - \\
Female & 78 & 31.30 & - \\
Male & 249 & - & 33.82 \\
Age & 249 & - & 10.86 \\
Length of professional experience & 249 & - & 0.45 \\
Number of postgraduate nursing certificates & & & \\
Academic level & 179 & 71.90 & - \\
Degree & 68 & 27.30 & - \\
Master's & 2 & 0.80 & - \\
Doctorate & & & \\
Specialized nursing degree & 148 & 58.60 & - \\
None & 69 & 27.70 & - \\
Psychiatric and mental health & 12 & 4.80 & - \\
Medical-surgical & 9 & 3.60 & - \\
Rehabilitation & 13 & 5.30 & - \\
Others & & & \\
Ward & 112 & 45.20 & - \\
Medical-surgical & 58 & 23.40 & - \\
Mental health & 78 & 31.40 & - \\
Others & & & \\
Working context & 169 & 68.10 & - \\
Hospital wards & 34 & 13.70 & - \\
Primary health care & 45 & 18.20 & - \\
Others & & & \\
Training in assessment tools & 198 & 79.50 & - \\
Yes & 51 & 20.50 & - \\
No & 34 & 13.70 & - \\
Training in confusion assessment and intervention & 36.10 & - \\
Acute confusion & 119 & 47.80 & - \\
Chronic confusion & & & \\
Acute and chronic confusion & & \\
None & & & - \\
\hline & & & \\
\hline
\end{tabular}


performed. While $57.80 \%$ reported that AC/delirium assessment tools were never used, $43 \%$ reported they thought such instruments should be frequently utilized and $35.30 \%$ said their use should be made obligatory.

A median of one tool for assessing AC/delirium was found, which suggests that the nurses are generally familiar with just one such instrument. The tools most commonly known are the Mini-Mental State Examination (MMSE) (53\%) and the Clock Drawing Test (27\%), neither of which is designed to test specifically for AC/delirium. Furthermore, $34 \%$ of the participants reported not knowing of any such tool. The participants reported, on average, being able to use just one of the tools listed, especially the MMSE (47\%) and the Clock Drawing Test (19\%). On the other hand, $41 \%$ reported not being able to apply any of the listed instruments.

In spite of these negative results, $91.60 \%$ reported thinking that such tools would be beneficial for diagnosis processes (due to their contribution to the increase in assessment accuracy and objectivity-40.60\%) while $93.20 \%$ felt that such tools would help nurses target their practice to patients' needs (since they would permit the selection of appropriate interventions as suggested by the assessment-45.90\%). Nevertheless, $64.30 \%$ of the participants remarked that, in their place of work, no distinction was normally made between the assessment of AC and CC.

When speaking of their processes for diagnosing AC, the nurses mentioned the assessment of patient orientation (76\%), stage of consciousness (66\%), and psychomotor behavior (65\%). However, little use of tools is mentioned: MMSE-13\%; Clock Drawing Test-8\%; Neecham Confusion Scale-6\%; Confusion Assessment Method (CAM) $1 \%$; CAM-Intensive Care Unit (CAM-ICU) - $2 \%$.

When faced with patients with $\mathrm{AC}, 81.90 \%$ of the respondents described their principal nursing concern as being patient safety. Paradoxically, only $8.40 \%$ cited the reduction of patient confusion as their main objective.

No attempt, in the clinical context, to distinguish between interventions for $\mathrm{AC}$ and those for $\mathrm{CC}$ was reported by $65.90 \%$ of nurses. Furthermore, $79.10 \%$ described the lack of any systematized procedures for confusion intervention. In cases of $\mathrm{AC}$, the most common interventions related to the management of the physical environment $(80 \%)$ and the management of communication (71\%). The data are similar in CC patients, with $81 \%$ and $62 \%$ of efforts being directed toward, respectively, physical environment and communication management. These interventions echo the opinions of the nurses that indicated that physical environment and communication are the most useful intervention options in $\mathrm{AC}$ cases $(75 \%$ and $71 \%$, respectively) and in cases of CC (78\% and $74 \%$, respectively). In both AC and CC patients, the figures fell short of those expected for those interventions recommended in the literature (Marques, 2012) such as reality orientation (57\% in $\mathrm{AC}$ and $50 \%$ in CC) and validation therapy (39\% in AC and $46 \%$ in CC).

As far as the prevention of and intervention for confusion is concerned, $86.3 \%$ of nurses reported a decisive role for nurses in this area. This is related to the fact that the nurse is the healthcare professional who works mostly closely with patients and for the longest periods ( $48.10 \%)$, and who is able to assess and provide the broadest possible range of interventions $(23.40 \%)$.

Finally, a majority of nurses use the apparently more appropriate concept of AC proposed by the NANDA (North American Nursing Diagnosis Association) International (2010) $(72.40 \%)$ while only $2.40 \%$ reported using the potentially less suitable notion of AC (that of CC, according to NANDA International (2010)). As for the concept of CC utilized in nurses clinical practice, $89.10 \%$ reported using the supposedly more appropriate concept (that of CC, according to NANDA International (2010)) while only $0.40 \%$ used the less suitable one (that of AC, according to NANDA International (2010)). As for the causes of AC, only $24.20 \%$ of nurses were able to correctly identify the potential causes of the phenomenon, although only $0.80 \%$ of respondents were completely off the mark. On the other hand, only $11.70 \%$ of nurses were adequately familiar with the whole range of potential causes of CC. Nevertheless, only $1.60 \%$ of participants were totally wrong.

Table 2 illustrates some demographic traits that appear to determine nurses' knowledge and interventions provided.

Table 2. Inferential Statistics-Student's t-Tests and One-Way ANOVA

\begin{tabular}{|c|c|c|c|}
\hline Tests of differences & $t$ & $\boldsymbol{F}$ & $d f$ \\
\hline Gender versus number of AC/delirium assessment tools familiar to nurses & $2.13^{*}$ & - & 90.60 \\
\hline Age versus perception of the benefits of using AC assessment tools for appropriate intervention & $-2.74 * *$ & - & 247 \\
\hline $\begin{array}{l}\text { Length of professional experience versus perception of the benefits of using AC assessments for } \\
\text { appropriate intervention }\end{array}$ & $-2.85^{* *}$ & - & 247 \\
\hline Specialization versus number of $\mathrm{AC} /$ delirium assessment tools able to use & - & $3.71 * *$ & 6.246 \\
\hline $\begin{array}{l}\text { Theoretical training about the use of assessment tools versus number of AC/delirium assessment tools } \\
\text { familiar to nurses }\end{array}$ & $5.37 * * *$ & - & 236.67 \\
\hline $\begin{array}{l}\text { Theoretical training about the use of assessment tools versus number of AC/delirium assessment tools } \\
\text { able to use }\end{array}$ & $4.37 * * *$ & - & 247 \\
\hline
\end{tabular}

${ }^{*} p<.05 .{ }^{* *} p<.01 .{ }^{* * *} p<.001$. 
Table 3. Inferential Statistics-Mann-Whitney Tests

\begin{tabular}{|c|c|c|}
\hline Tests of differences & $U$ & $M_{1} / M_{2}$ \\
\hline Perceived ideal frequency of use of $\mathrm{AC} /$ delirium assessment tools mental health versus medical-surgical wards & $2,561.00 *$ & $3.84 / 4.21$ \\
\hline Perceived ideal frequency of use of AC/delirium assessment tools mental health wards versus emergency & $288.50 * *$ & $3.84 / 4.63$ \\
\hline $\begin{array}{l}\text { Number of AC/delirium assessment tools familiar to nurses specialized in psychiatric and mental health versus maternal } \\
\text { health and obstetrics }\end{array}$ & $40.00 * *$ & $3.22 / 0.40$ \\
\hline Number of AC/delirium assessment tools familiar to nurses specialized in psychiatric and mental health versus pediatrics & $9.00 * *$ & $3.22 / 0.001$ \\
\hline $\begin{array}{l}\text { Number of AC/delirium assessment tools familiar to nurses specialized in psychiatric and mental health versus } \\
\text { medical-surgical }\end{array}$ & $205.00 * *$ & $3.22 / 1.17$ \\
\hline $\begin{array}{l}\text { Number of AC/delirium assessment tools familiar to nurses specialized in psychiatric and mental health versus public } \\
\text { health }\end{array}$ & $54.00 * *$ & $3.22 / 0.60$ \\
\hline $\begin{array}{l}\text { Number of AC/delirium assessment tools familiar to nurses specialized in psychiatric and mental health versus } \\
\text { non-specialized nurses }\end{array}$ & $2,503.00 * * *$ & $3.22 / 1.83$ \\
\hline Theoretical training in the use of $\mathrm{AC} /$ delirium assessment tools versus regularity of use of $\mathrm{AC} /$ delirium assessment tools & $4,044.50 *$ & - \\
\hline $\begin{array}{l}\text { Regularity of use of AC/delirium assessment tools in nurses with theoretical training in the CC assessment and } \\
\text { intervention versus nurses without theoretical training }\end{array}$ & $213.00^{*}$ & $2.50 / 1.51$ \\
\hline $\begin{array}{l}\text { Regularity of use of } \mathrm{AC} / \text { delirium assessment tools in nurses with theoretical training in the AC/CC assessment and } \\
\text { intervention versus nurses without theoretical training }\end{array}$ & $4,038.00 * *$ & $1.94 / 1.51$ \\
\hline $\begin{array}{l}\text { Number of } \mathrm{AC} / \text { delirium assessment tools familiar to nurses with theoretical training in } \mathrm{AC} \text { assessment and intervention } \\
\text { versus nurses with theoretical training in } \mathrm{AC} \text { and } \mathrm{CC}\end{array}$ & $942.50 * *$ & $1.32 / 2.67$ \\
\hline $\begin{array}{l}\text { Number of AC/delirium assessment tools familiar to nurses with theoretical training in the CC assessment and } \\
\text { intervention versus nurses without theoretical training }\end{array}$ & $166.00 *$ & $8.17 / 1.02$ \\
\hline $\begin{array}{l}\text { Number of AC/delirium assessment tools familiar to nurses with theoretical training in the AC/CC assessment and } \\
\text { intervention versus nurses without theoretical training }\end{array}$ & $2,498.00 * * *$ & $2.67 / 1.02$ \\
\hline
\end{tabular}

${ }^{*} p<.05 .{ }^{* *} p<.01 .{ }^{* * *} p<.001$.

Age and length of professional experience were inversely related to the perception of nurses about the benefits of using tools for evaluating $\mathrm{AC}$ in order to plan the most suitable nurse care. Male nurses had greater familiarity with $\mathrm{AC} /$ delirium assessments. Moreover, nurses with theoretical training in AC/delirium assessment tools had more knowledge of the instruments and were able to use more of them. Differences also appeared regarding the area of specialization and the number of tools respondents were familiar with. Psychiatric and mental health nurses $(M=2.12 ; S D=3.45)$ knew and used more tools than their non-specialized colleagues $(M$ $=0.81 ; S D=1.25)$. A small yet significant correlation was also found between the number of nursing postgraduate certificates held and the number of assessment tools they knew about and were able to use.

Table 3 illustrates that, for example, nurses in medicalsurgical wards and in emergency departments felt a greater need for regular use of assessment tools than those in mental health wards. Nurses with theoretical training in AC/delirium assessment tools reported using them more regularly. Nurses with training in assessing and intervening in $\mathrm{AC}$ and $\mathrm{CC}$, for example, reported using the instruments more frequently. Nurses specialized in psychiatric and mental health, for example, were familiar with more tools than those in maternal health and obstetrics, child health and pediatrics, medicalsurgical, and public health, and more than those nonspecialized nurses. Nurses with training in AC and CC, for example, were familiar with a greater number of instruments than those who had had no such training. A set of associations emerged from the analysis and the most relevant is presented in Table 4.

\section{Discussion}

Definite gaps appear in the level of assessment of $\mathrm{AC} /$ delirium, including in the regularity of the use of assessment tools, which might partly explain the underdiagnosis of the phenomenon (Silva et al., 2011). Overall, however, that may not be true as some studies have suggested that even with the use of AC/delirium assessment tools (in this case, the CAM), $75 \%$ of nurses were not able to recognize delirium when it was, in fact, present (Rice et al., 2011). These numbers support those of earlier studies (Inouye, Foreman, Mion, Katz, \& Cooney, 2001) suggesting that nurses with recourse to the CAM, although they rarely identified the presence of delirium when it was absent in their patients, also frequently failed to diagnose its presence. Nevertheless, the results of the current study appear to suggest that nurses were aware of the importance of the regular use of instruments for assessing $\mathrm{AC} /$ delirium.

However, gaps were reported in participants' knowledge and use of AC/delirium assessment tools which supports similar findings in other studies that nurses mostly rely on observation to assess AC/delirium (Forsgren \& Eriksson, 2010), which is obviously inadequate as found in the study by Mistarz, Eliott, Whitfield, and Ernest (2011). This research 
Table 4. Inferential Statistics_Chi-Square Tests

\begin{tabular}{|c|c|c|c|}
\hline Tests of association & $\chi^{2}$ & $d f$ & $\varphi c$ \\
\hline $\begin{array}{l}\text { Ward versus perception of the benefits of using AC/delirium assessment tools for the identification of the nursing } \\
\text { diagnosis }\end{array}$ & $25.09 * *$ & 10 & 0.32 \\
\hline Ward versus perception of the benefits of using AC/delirium assessment tools for appropriate intervention & $26.55^{* *}$ & 10 & 0.33 \\
\hline $\begin{array}{l}\text { Work context versus perception of the benefits of using AC/delirium assessment tools for the identification of the } \\
\text { nursing diagnosis }\end{array}$ & $15.94^{*}$ & 7 & 0.25 \\
\hline Work context versus perception of the benefits of using $\mathrm{AC} /$ delirium assessment tools for appropriate intervention & $21.21 * *$ & 7 & 0.29 \\
\hline Nursing specialization versus knowledge of causes of AC & $63.42 * *$ & 36 & 0.21 \\
\hline Nursing specialization versus knowledge of causes of CC & $52.83^{* *}$ & 23 & 0.23 \\
\hline Care goals for $\mathrm{AC}$ patients versus theoretical training about confusion assessment and intervention & $26.03 * *$ & 9 & 0.19 \\
\hline
\end{tabular}

${ }^{\star} p<.05 .{ }^{* *} p<.01 .{ }^{* * *} p<.001$.

compared diagnoses based on pure observation versus those carried out with CAM-ICU, and found that nurses relying merely on observation identified AC/delirium in only $27 \%$ of the cases in which it was present, while correctly identifying $92 \%$ of an absence of delirium.

Nurses' perception of the main care goals for AC patients echoed those reported in previous research. The main objective of nurses is patient safety, which is understandable due to the high risk of falls in patients with delirium. Some studies have found, for example, that delirium may correlate with a 6-fold increase in risk of falls (Lakatos et al., 2009). However, some have argued (Marques, 2012) that reducing confusion might be more efficient, since, in addition to dealing with the signs and symptoms, it should contribute, at least indirectly, to the prevention of risks. In other words, to the extent that nurses devote greater attention and effort to attending to confusion, the greater will be the importance they accord to it.

Our results supported those of Steen et al. (2013), finding little systematized intervention for confusion. Marques (2012), on the other hand, found that nurses do, in fact, distinguish between AC and CC patients when prescribing nursing intervention since they felt that $\mathrm{AC}$ patients promised greater potential for successful intervention. Our participants, on the contrary, reported making no distinction regarding interventions for AC and CC patients. Such interventions, as were offered both in AC and CC cases, were predominantly of the autonomous rather than the interdependent type. Another worrying fact is that the nurses often failed to provide sufficient reality orientation, a technique of proven efficacy in CC patients (Woods, Aguirre, Spector, \& Orrell, 2012). Nor did they regularly provide validation therapy, whose effectiveness has not yet been conclusively proven (Neal \& Wright, 2009), despite initially positive results (Toseland et al., 1997). Happily, the immobilization of patients and their physical restriction behind bars are not listed among the main interventions for AC and CC patients. However, $40-50 \%$ of respondents mentioned that they are some of the most common interventions in $\mathrm{AC}$ patients and that they are used in between $30 \%$ and $50 \%$ of CC cases. These types of actions are oftentimes intended to protect patients (The American Geriatrics Society, 2008). However, physical restriction appears to have a negative impact on patients' quality of life (Karlsson, Bucht, Rasmussen, \& Sandman, 2000), being associated with a rise in behavioral alterations, lessened cognitive performance, increase in the number of falls, less independence of deambulation and in daily activities, and an increase in the number of pressure ulcers and contractures (Castle \& Engberg, 2009).

As far as nurses' knowledge about AC and CC is concerned, they appear to be able to distinguish the clinical conditions, although they lack some knowledge about the causes of the same. The results further support those found in other studies (e.g., Hare, Wynaden, McGowan, Landsborough, \& Speed, 2008), pointing out that that nurses' knowledge of delirium and its risk factors is insufficient. It is shown that training in cognitive assessments in general, and delirium in particular, should be incorporated into basic nursing education in order to achieve healthcare gains and considerable cost reductions.

The results of inferential statistics allow us mostly to identify potential approaches for improving the quality of nursing care of AC or CC patients. Thus, as far as AC/delirium assessment tools are concerned, the findings suggest that nurses with theoretical training about assessment tools not only know about more instruments but also are able to use them and, in fact, do so. It would appear to be important, therefore, to invest in greater training in this area, which should raise nurses' awareness of the importance of undertaking continual education and of using $\mathrm{AC} /$ delirium instruments as research has proven useful (Gesin et al., 2012). Equally important is investment in training dealing with the assessment of and intervention with confusion, since the findings suggest that nurses with such training have command of a greater number of $\mathrm{AC} /$ delirium tools, using them more regularly.

Finally, these results suggest that younger nurses are more aware of the importance of assessment tools, which may reflect changes in training. It was also observed that nurses specialized in psychiatric and mental health nursing are among those aware of greater numbers of $\mathrm{AC} /$ delirium assessment tools and who are able to use them, which is to be 
expected since the focus on "Confusion" nursing diagnosis makes up part of the specialization in psychiatric and mental health nursing. Paradoxically, however, most studies of AC worldwide have arisen from specialists in the medicalsurgical area (the same is not true, however, for CC).

One of the limitations of this study is that the sample included a great number of nurses specialized in psychiatric and mental health nursing relative to other specializations, which may have had an impact on the results. Furthermore, the fact that the sample was non-probabilistic is another significant drawback relative to the generalizability of the results (since it is not possible to know whether the sample is representative of the target population), making it impossible to estimate the sampling error, which may have influenced the results. Although the study was conducted in Portugal, with Portuguese nurses, the findings seem to be transferable to other countries, since nursing in Portugal has some similarities, for example, to the United States and to other European countries.

Despite the limitations, the results of this study support the findings of Marques (2012). The current study, however, had a broader aim, as it sought to understand as well CC interventions by nurses. Further research, therefore, should take a multi-centric approach in order to obtain data permitting comparisons between various sociocultural contexts, with larger samples and using questionnaires that have been translated and validated in a variety of contexts. Even so, this research offers contributions in the area of training to the extent that it raises consciousness of the importance of nurses' attention to confusion. In clinical practice as well, it calls nurses' attention to the need for more accurate assessments and the need to employ interventions with greater levels of efficacy for patients with confusion. This study may also serve as a starting point for the design of best practice guidelines for confusion diagnosis and intervention, which should greatly improve the quality of care.

\section{Implications for Nursing Practice}

The findings from this study can be considered as relevant for nursing schools in order to improve nurses' training. Considering that nurses' knowledge and practices about diagnosis and intervention in patients with acute or CC fell short of what is recommended in the literature, and that younger nurses with better academic training and more postgraduate nursing degrees are more aware to the importance of conducting formal assessments of patients with confusion, it remains clear that nursing training regarding confusion assessment should be incorporated into basic nursing education. Thus, it seems relevant to integrate $\mathrm{AC}$ and $\mathrm{CC}$ contents into nursing curricula, such as information about available delirium assessment instruments (e.g., the CAM) and about available AC assessment instruments (e.g., the Neecham Con- fusion Scale, an instrument developed by nurses and for nurses specifically to assess AC). The integration of evidencebased interventions for confusion into nursing curricula also seems to be relevant, particularly reality orientation and validation therapy, both reported in the literature as promising to attenuate confusion (acute or chronic). In terms of clinical practice, this study points to the need of reformulating practices related to the assessment and intervention for AC and CC. Thus, it seems essential to increase the use of AC/delirium assessment instruments as a way to reduce the underdiagnosis of those phenomena, and to carry out more evidence-based interventions, meaning interventions more focused on the attenuation of confusion, and not only on the patient's safety promotion.

This study can be considered as the baseline to the development and evaluation of a guideline regarding AC and CC diagnosis and nursing intervention. The development of nursing best practice guidelines is absolutely essential to advocate for the scientific character of nursing discipline, and to move toward a nursing science more and more evidence based, and not only based on professional experience. Considering the findings from this study, it seems now possible to develop a nursing best practice guideline from nurses' knowledge and practices in order to guarantee that, in fact, it can be applied in the clinical practice.

In conclusion, the present study aimed to highlight the importance of the information about nurses' knowledge and practices as a way of making lecturers and nurses aware of the need for paying attention to confusion as a nursing intervention area; making nurses aware of the existence of an instrument of choice to assess AC (Neecham Confusion Scale), whose use in the clinical practice seems to be really important; and raising awareness of the need for research about confusion, especially at the level of differential diagnosis with similar nursing phenomena.

\section{References}

Adamis, D., Sharma, N., Whelan, P. J. P., \& Macdonald, A. J. D. (2010). Delirium scales: A review of current evidence. Aging \& Mental Health, 14(5), 543-555. doi:10.1080/ 13607860903421011

The American Geriatrics Society. (2008). AGS Position Statement on Restraint Use. USA.

Castle, N. G., \& Engberg, J. (2009). The health consequences of using physical restraints in nursing homes. Medical Care, 47(11), 1164-1173. doi:10.1097/MLR.0b013e3181b58a69

Cole, C. S., Williams, E. B., \& Williams, R. D. (2006). Assessment and discharge planning for hospitalized older adults with delirium. Medsurg Nursing, 15(2), 71-76.

Devlin, J. W., Fong, J. J., Howard, E. P., Skrobik, Y., McCoy, N., Yasuda, C., \& Marshall, J. (2008). Assessment of delirium in the intensive care unit: Nursing practices and perceptions. American Journal of Critical Care, 17(6), 555-565. 
Forsgren, L. M., \& Eriksson, M. (2010). Delirium-awareness, observation and interventions in intensive care units: A national survey of Swedish ICU head nurses. Intensive and Critical Care Nursing, 26(5), 296-303. doi:10.1016/j.iccn 2010.07.003

Fortin, M. F., Côté, J., \& Filion, F. (2009). Fundamentos e etapas do processo de investigação. Loures: Lusodidacta.

Gesin, G., Russell, B. B., Lin, A. P., Norton, H. J., Evans, S. L., \& Devlin, J. W. (2012). Impact of a delirium screening tool and multifaceted education on nurses' knowledge of delirium and ability to evaluate it correctly. American Journal of Critical Care, 21(1), e1-e11. doi:10.4037/ajcc2012605

Hare, M., Wynaden, D., McGowan, S., Landsborough, I., \& Speed, G. (2008). A questionnaire to determine nurses' knowledge of delirium and its risk factors. Contemporary Nurse, 29(1), 23-31.

Inouye, S. K., Foreman, M. D., Mion, L. C., Katz, K. H., \& Cooney, L. M., Jr. (2001). Nurses' recognition of delirium and its symptoms: Comparison of nurse and researcher ratings. Archives of Internal Medicine, 161(20), 2467-2473. doi:10.1001/archinte.161.20.2467

Karlsson, S., Bucht, G., Rasmussen, B. H., \& Sandman, D. (2000). Restraint use in elder care: Decision making among registered nurses. Journal of Clinical Nursing, 9(6), 842-850. doi:10.1046/ j.1365-2702.2000.00442.x

Lakatos, B. E., Capasso, V., Mitchell, M. T., Kilroy, S. M., Lussier-Cushing, M., Sumner, L., .. . Stern, T. A. (2009). Falls in the general hospital: Association with delirium, advanced age, and specific surgical procedures. Psychosomatics, 50(3), 218-226. doi:10.1176/appi.psy.50.3.218

Marques, P. (2012). O doente idoso com confusão e a acção de enfermagem. Loures: Lusociência.

Mistarz, R., Eliott, S., Whitfield, A., \& Ernest, D. (2011). Bedside nurse-patient interactions do not reliably detect delirium: An observational study. Australian Critical Care, 24(2), 126-132. doi:10.1016/j.aucc.2011.01.002

Neal, M., \& Wright, P. B. (2009). Validation therapy for dementia. Cochrane Database of Systematic Reviews, Article no. 1. doi:10.1002/14651858.CD001394

Neves, H. (2008). Confusão aguda no doente hospitalizado: Adaptação cultural e validação da escala de confusão neecham (Unpublished master's dissertation). Instituto de Ciências da Saúde, Universidade Católica do Porto, Portugal.

North American Nursing Diagnosis Association International. (2010). Diagnósticos de enfermagem da NANDA: Definições e classificação 2009-2011. Porto Alegre: Artmed.
Park, M., Delaney, C., Maas, M., \& Reed, D. (2004). Using a Nursing Minimum Data Set with older patients with dementia in an acute care setting. Journal of Advanced Nursing, 47(3), 329-339. doi:10.1111/j.1365-2648.2004.03097.x

Passos, J., Sequeira, C., \& Fernandes, L. (2012). The needs of older people with mental health problems: A particular focus on dementia patients and their carers. International Journal of Alzheimer's Disease. doi:10.1155/2012/638267

Rapp, C. G., Wakefield, B., Kundrat, M., Mentes, J., Tripp-Reimer, T., Culp, K., ... Onega, L. L. (2000). Acute confusion assessment instruments: Clinical versus research usability. Applied Nursing Research, 13(1), 37-45. doi:10.1016/S0897 -1897(00)80017-8

Rice, K. L., Bennett, M., Gomez, M., Theall, K. P., Knight, M., \& Foreman, M. D. (2011). Nurses' recognition of delirium in the hospitalized older adult. Clinical Nurse Specialist, 25(6), 299-311. doi:10.1097/NUR.0b013e318234897b

Scott, P., McIlveney, F., \& Mallice, M. (2013). Implementation of a validated delirium assessment tool in critically ill adults. Intensive Critical Care Nursing, 29(2), 96-102. doi:10.1016/j iccn.2012.09.001

Sendelbach, S., Guthrie, P. F., \& Schoenfelder, D. P. (2009). Acute confusion/delirium. Journal of Gerontological Nursing, 35(11), 11-18. doi:10.3928/00989134-20090930-01

Silva, R., Silva, A. P., \& Marques, P. (2011). Analysis of a health team's records and nurses' perceptions concerning signs and symptoms of delirium. Revista Latino-Americana de Enfermagem, 19(1), 81-89. doi:10.1590/S0104 $-11692011000100012$

Steen, E., Detroyer, E., Milisen, K., Lambert, M., Boland, B., \& Van Den Noortgate, N. (2013). Management of delirium on acute geriatric wards: A survey in Belgian hospitals. European Geriatric Medicine, 4(3), 209-213. doi:10.1016/j.eurger.2013 .04 .006

Toseland, R. W., Diehl, M., Freeman, K., Manzanares, T., Naleppa, M., \& McCallion, P. (1997). The impact of validation group therapy on nursing home residents with dementia. Journal of Applied Gerontology, 16(1), 31-50. doi:10.1177/ 073346489701600102

Wong, C. L., Holroyd-Ledue, J., Simel, D. L., \& Straus, S. E. (2010). Does this patient have delirium? Value of bedside instruments. Journal of the American Medical Association, 304(7), 779-786. doi:10.1001/jama.2010.1182

Woods, B., Aguirre, E., Spector, A. E., \& Orrell, M. (2012). Cognitive stimulation to improve cognitive functioning in people with dementia. Cochrane Database of Systematic Reviews, Article no. 2. doi:10.1002/14651858.CD005562.pub2 